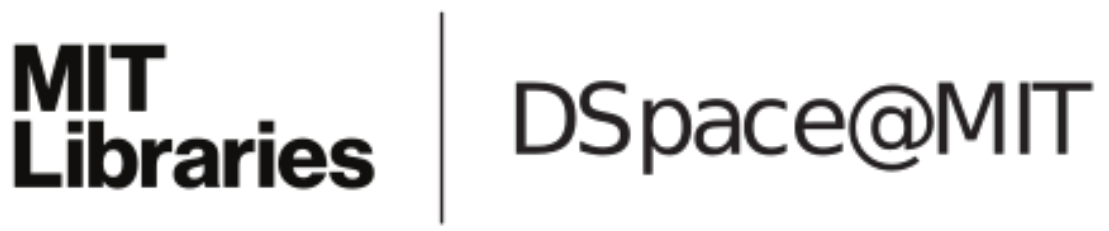

\author{
MIT Open Access Articles
}

Conceptual Model Development for Holistic Building Fire Safety Performance Analysis

The MIT Faculty has made this article openly available. Please share how this access benefits you. Your story matters.

Citation: Park, Haejun et al. "Conceptual Model Development for Holistic Building Fire Safety Performance Analysis." Fire Technology 51.1 (2015): 173-193.

As Published: http://dx.doi.org/10.1007/s10694-013-0374-1

Publisher: Springer US

Persistent URL: http://hdl.handle.net/1721.1/105238

Version: Author's final manuscript: final author's manuscript post peer review, without publisher's formatting or copy editing

Terms of use: Creative Commons Attribution-Noncommercial-Share Alike 


\title{
Conceptual Model Development for Holistic Building Fire Safety Performance Analysis
}

\author{
Haejun Park*, Brian J. Meacham and Nicholas A. Dembsey, Department of \\ Fire Protection Engineering, Worcester Polytechnic Institute, 100 Institute \\ Road, Worcester, MA 01609, USA
}

Mark Goulthorpe, Department of Architecture, Massachusetts Institute of

Technology, 77 Massachusetts Avenue, Cambridge, MA 02139, USA

Received: 7 August 2013/Accepted: 15 November 2013

\begin{abstract}
The evaluation of building performance during fires is a critical step in designing appropriate strategies. Inappropriate or incomplete performance evaluations can mislead fire safety design solutions, which may in turn result in unacceptable loss of life or building damage from fire. While various building fire safety performance evaluation models have been developed, they focus primarily on 'hard' characteristics, such as building construction type and fire protection measures. However, 'soft' characteristics, such as building design (architectural) features and occupant characteristics, which also significantly influence building fire safety performance, have not been comprehensively taken into account. In the current study, two conceptual performance models: a generic fire response model and an integrated characteristic interaction model, have been developed to represent the holistic building fire safety performance considering the effects of both hard and soft characteristics. In these models, various cause-effect relationships among building, people, and fire characteristics are identified at the different levels of detail. Based on the conceptual models, a quantitative model utilizing the parameter ranking method and weighted sum method, which are commonly used in analytical hierarchy process, is proposed as a tool to help evaluate building fire safety performance and to assist decision making process of developing fire safety design solutions.
\end{abstract}

Keywords: Building fire safety, Performance evaluation, Holistic fire safety performance, Alternative fire safety design

\section{Introduction}

Building fire safety performance is largely a function of building, people and fire attributes, and is independent of the regulatory system or fire safety design approach applied. It should be noted that while the regulation prescribes necessary elements required to a given building which significantly influence the fire safety performance, the regulatory system generally defines the design and assessment approach for the necessary elements. In a prescriptive-based building regulatory system, the codes which prescribe detailed requirements for fire safety design

\footnotetext{
* Correspondence should be addressed to: Haejun Park, E-mail: prkhjn@yahoo.com
} 
serve as the criteria for both design and performance evaluation. In other words, once a building complies with the code requirements, fire safety design and subsequent building fire safety performance are considered to be appropriate and acceptable. If the expected performance changes, or critical flaws in the code requirements are found, the codes are revised and updated to satisfy a new level of fire safety performance. This is why major updates of the codes are often seen after large loss fires.

In a performance-based building regulatory system, building fire safety performance analysis draws more attention from the fire protection engineers, as they are generally expected to demonstrate that the proposed fire safety design solution satisfies the performance objectives stated in the code [1]. Although means and methodologies for the evaluation are not generally included in the codes, guidance materials are available such as the international fire engineering guides [2] or the SFPE engineering guides for various topics.

Despite these guides, it is very challenging to comprehensively and adequately assess the fire safety performance of a building and reflect the outcome of the assessment into the fire safety design solution. There may be various reasons for this. First, predicting building fire safety performance is a very complex problem. Slight changes of influencing characteristics, such as the amount of fuel contents and occupant locations, can lead to significantly different outcomes, and these characteristics are typically not readily known and randomly vary. Second, experiments in a real environment, which are often conducted in other engineering fields to evaluate the performance of designs, are almost impossible in fire safety engineering. Due to the fire damage and ethical concerns, fire and evacuation experiments are generally conducted in a controlled environment which may not represent real conditions. Small and intermediate-scale experiments are often conducted, but no valid methodology exists to comprehensively predict the full scale results from the small and intermediate scale tests. Thirdly, challenges such as uncertainty regarding the tools and data used in the analysis, the capability of fire safety engineers conducting performance analysis, and justifiability of design fire scenarios are also understood as the reasons for the difficulties of fire safety performance assessment. In addition to these, building fire safety performance is influenced by so many individual factors and their interactions during fire incidents that it is difficult to identify and formulate them thoroughly in the analysis.

To address the complexity by reducing the problem to manageable components, and to account for some of the uncertainty and variability in the process, multiple approaches for evaluating building fire safety performance and informing design strategies have been developed. While the prescriptive-based approach continues to be dominantly practiced in some countries, a systems approach for fire safety performance evaluation and design was introduced and explored by fire safety researchers in the 1970s [3], the outcome of which resulted in basis for current performance-based design approaches. In the systems approach, the building and the fire are viewed as critical system components, and the fire safety performance such as life safety and property protection was considered as a result of influences among the system components [4]. In the late 1980s, 
HAZARD I software which reflected building, fire, and occupants as a system was developed in UK. By accounting for various factors on the analysis result of a fire scenario, the influence of changes in the factors on the likely outcome of fires could be analyzed [5]. The concept used HAZARD I is utilized in the current research. Several pioneering research were also conducted in the USA [6, 7]. Among those, general service administration (GSA)'s guide to goal-oriented systems approach to building fire safety became an impetus for further development of other models such as the building fire safety evaluation method (BFSEM) developed by Fitzgerald, the fire safety evaluation system (FSES) in NFPA 101A, guide on alternative approaches to life safety, and NFPA 550, fire safety concepts tree (FSCT) [8].

The BFSEM uses network diagrams which follows the sequential fire development from ignition to fire spread beyond the room of origin with various sub-level events $[9,10]$. The FSES is fundamentally a parameter ranking method for the evaluation of life safety performance. It basically assigns weighted points to various fire safety parameters and the accumulated point represents the level of fire safety. Similar parameter ranking approaches were also developed in UK [11, 12] and Hong Kong [13-15]. Whereas the BFSEM and FSES use quantified values, the FSCT is a structured tree diagram without any quantification. It divides the fire safety objectives into two: prevent fire ignition and manage fire impact, and each objective branches further being connected with necessary means and strategies to achieve the objective using "and" or "or" gate.

Most of these models, however, have focused primarily on 'hard' characteristics such as physical building systems and components and fire protection measures which were typically included in prescriptive codes. They did not comprehensively take into account 'soft' characteristics such as building design features, occupant activities, and the interactions among the soft characteristics and between soft and hard characteristics. This is partly because soft characteristics have not been considered as proper subjects of prescriptive codes due to their high variability and difficulties to control by codes, despite the recognition of their significant effects on building fire safety performance [16]. However, in performance-based fire safety design scheme, both hard and soft characteristics need to be included in the performance analysis since they are also significant attributes to the building fire safety performance.

Since many developed European and Asian countries have already adopted or are moving toward performance-based codes [17], and alternative fire safety design methods are allowed even in the countries that implement the prescriptive-based codes, such as the USA, the importance of appropriate assessment tools and methodologies of building fire safety performance will become increased and demanded. In this context, the current study proposes conceptual models to evaluate building fire safety performance and to develop alternative fire safety design solutions. Based on these models, a quantitative model is developed as a tool to evaluate building fire safety performance and to assist decision making process of developing fire safety design solutions. 


\section{A Holistic Approach for Building Fire Safety Performance}

As implemented in the systems approach, building fire safety performance is largely a function of the influence of building, people (occupants and firefighters), and fire (fuel contents) characteristics on the development, spread, and impact of fire on a building and people. For example, proper exit signage as a building characteristic can guide occupants to proper exits in time avoiding fire-induced hazardous environments during fire conditions, which increases the fire safety performance in terms of life safety. Likewise, any individual fire protection measures such as fire suppression systems, detection, alarm, and notification systems, means of egress, and fire and smoke barrier as building characteristics can increase the fire safety performance.

In addition, occupant familiarity to the exit location as a people characteristic can influence the fire safety performance. Choosing an appropriate exit route is one of the critical characteristics for effective occupant egress, and it generally takes less time for occupants who are familiar with the space layout to understand the fire situation and to plan appropriate exit routes. A simple and intuitively designed floor plan can increase the occupants' space familiarity, especially in building uses such as hospitals, large shopping malls, or hotels. In this case, the interactions between building characteristics (building use and floor plan) and a people characteristic (occupant familiarity to the space) influence the fire safety performance. Similarly, many characteristics of building, people, and fire have some degrees of dependency on each other and their interactions can influence the building fire safety performance.

The occupant familiarity also bring about the effects of building-people interactions during the normal building operation (non-fire or non-emergency conditions) on the building fire safety performance during fire conditions. Although occupant familiarity may vary depending on the floor plan complexity and building uses, it is generally expected to be gradually established while occupants experience the space of a building during the normal building operation. Therefore, occupants' exit route selection during fire conditions which is affected by the familiarity is influenced by the occupants' space perception during normal building operation. In other words, if occupants often use a specific exit in a normal building operation, it is highly likely that the occupants would use the same specific exit in fire conditions, and the rest exits are not much accessed by occupants due to the learned irrelevance regardless of their proximity or convenience [18].

The characteristics identified above may be categorized into two sets: hard characteristics and soft characteristics. The exit signage is a physical component specifically designed for fire conditions, and generally fire engineers pay good attention to them. However, building use, floor plan complexity, familiarity, and occupant's space experience can be widely different from building to building. They are also associated with other building objectives than fire safety such as aesthetics, space efficiency, and occupant comfort and their design is determined (or influenced) by other stakeholders with a less focus on their effects on fire safety performance. Some of the soft characteristics such as building use have been included both in 
the prescriptive codes and in various performance-based fire safety analysis methods, but others such as the relevance of occupant familiarity to floor plan complexity and occupant space perception have not been fully perceived by fire engineers. These characteristics are more related to architects as they are linked with space programming, floor plan, and the interactions of occupants with the built environment [19].

To help understand the exit route selection phenomenon during fire conditions, several characteristics from building and people components, occupant interaction with the space during the normal building operation, and multiple stakeholders who may have different perspectives and objectives, are identified above. Considering that occupant egress is associated with perception of fire, evacuation initiation, and movement in addition to the exit route selection, and that fire safety performance is also involved with other phenomena such as the responses of building fire safety systems and fire development phenomena in addition to occupant egress, the number of characteristics, interactions among them, and relevant stakeholders and their objectives become significantly increased. In addition, as these phenomena also depend on the conditional and chronological occurrence in the course of fire development, the building fire safety performance is, in fact, an extremely complex matter. This is why a comprehensive perspective is critically required to understand and evaluate the building fire safety performance.

\section{Development of Qualitative Models}

To holistically understand, examine, and interpret complex phenomena like the building fire safety performance, qualitative approaches are generally more beneficial than quantitative ones in the initial stages [20]. Two qualitative models, generic fire response model (GFRM) and integrated characteristic interaction model (ICIM), are developed.

\subsection{Generic Fire Response Model}

The GFRM is shown in Figure 1. It was designed to be a low resolution but comprehensive model that includes generic features and relationships of building, people, and fire responses. Even though it sacrifices some level of detail, it is beneficial as a 'first order' model when fire protection engineers need to look at the big picture of the fire safety performance and to discuss available fire safety strategies with stakeholders who may not be familiar with the fire-induced phenomena. The GFRM has a synergic effect when used with the FSCT as chronological features of fire development, building responses, and human activities which are pointed out as one of the limitations of FSCT [21] are implemented here.

In the GFRM, red, blue and green colors are used to represent the fire, building, and people component, respectively. Solid arrows indicate chronological event occurrence, and dotted arrows indicate the effects of one sub-component on the other. 


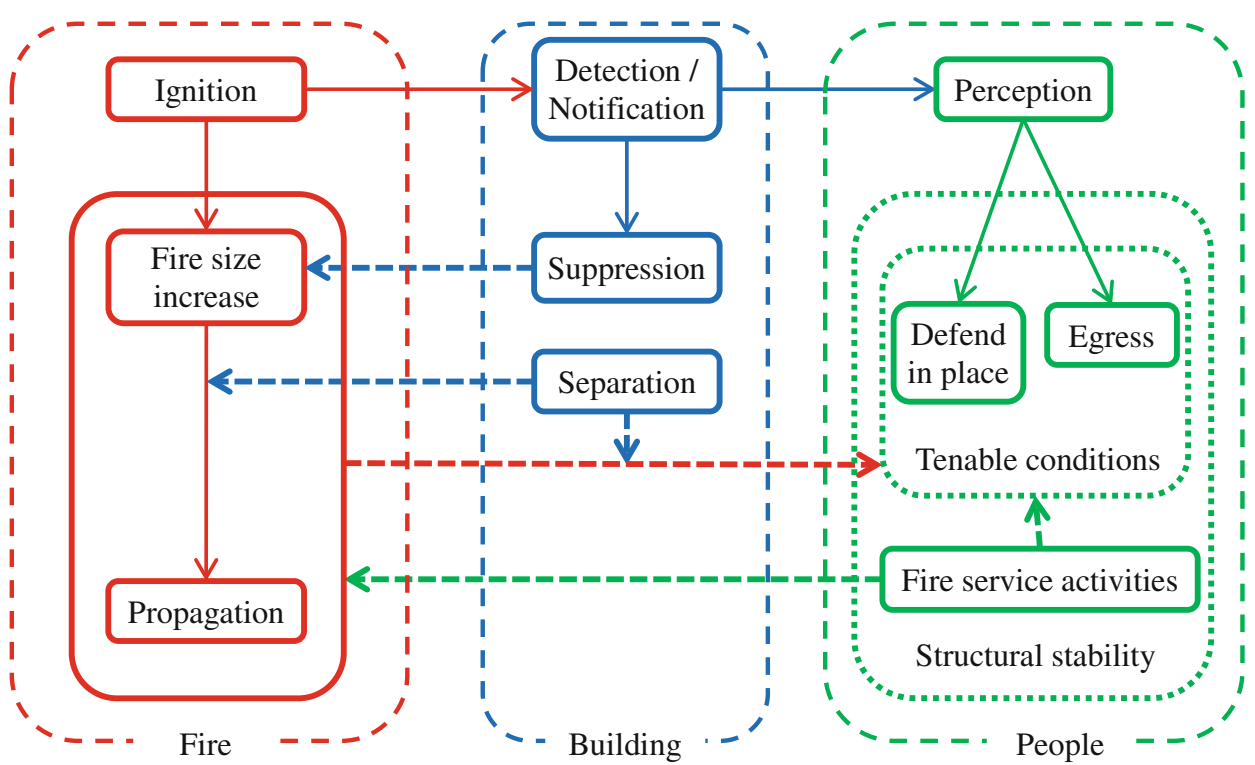

\section{Figure 1. A generic fire response model (GFRM).}

The fire component comprises the three sub-components: ignition, fire size increase and propagation, which follows the generic fire development process. The building component is composed of detection/notification, suppression, and separation. Ignition and subsequent combustion products activate the detection component which activates notification and suppression components. The suppression component controls fire size by preventing continuous combustion. The separation component has two effects: inhibiting the fire spread beyond the room of origin and physically separating hazardous fire products from people. This may include compartmentation, fire-rated building components and assemblies, and smoke control systems. The people component consists of two types: occupants and fire services. Occupants defend themselves where they are located or move to a safe place inside or outside the building once perceiving fire occurrence. Fire services conduct the mission of fire suppression and occupant rescue. With this simple model, one can quickly identify not only relationships, but importance of remaining components if some components are absent (e.g., if 'suppression' does not exist, 'separation' and 'detection' become more important as the only building systems). Note that the terms used for the components are conceptual explaining phenomena, not indicating specific fire safety measures.

Since the GFRM includes generic phenomena, there exist some exceptions which cannot be captured by literal interpretation of the model. For example, some suppression systems activate notification systems instead of being activated by detection systems. Occupants can perceive fire incidents not through a building notification system, but by directly seeing the fire or hearing from others. To include these cases, more arrows and sub-components are required in the model, 
which makes the model more precise, but the level of complexity is increased, which is not targeted in the GFRM.

The GFRM was constructed assuming that the users understand the dynamic features of the three components and their interactions along the fire development, from which they can communicate with other stakeholders more easily and develop proper fire safety strategies from a broad perspective. Important fire safety objectives are embedded in the GFRM. Property protection and life safety which are the most common building objectives can be identified by the fire component and people component. The GFRM shows that by controlling fire size and propagation, property protection from fire is achieved and by separating occupants from fire products, life safety is achieved. As noted above, it also shows and helps to describe impacts if certain components are unreliable or missing. For example, if a building site is located far away from the nearest fire station or heavy traffic conditions are generally expected in the fire service's travel route to the site, timely fire service activities may not be considered as a reliable option. In this case, other fire strategies such as suppression or separation whose effects are compatible to fire service activities need to be reinforced to mitigate the probable absence of fire services. As structured, the GFRM helps to explain the relative importance of the various components to achieving life safety objectives.

\subsection{Integrated Characteristic Interaction Model (ICIM)}

While the GFRM was developed to help, assess, and communicate concepts at a high level, it is recognized that much greater detail and complexity is needed to describe specific interactions within any given building or scenario. The ICIM was developed to provide this detail. The ICIM consists of three individual interaction models between building-people, people-fire, and fire-building. Among these, the interaction model between building-people is presented in Figure 2, and the other two models are included in another source [22]. It can be viewed as more detailed version of the GFRM. In each interaction model, various characteristics and cause-effect relationships among them are established.

Arrows are used to indicate the cause-effect relationships: arrow root for cause and head for effect, and dotted lines between two characteristics indicate that one is considered as a sub-characteristic of the other. Each of the three interaction models has two components assigned to the five columns: the first two columns are used for one of the two components, the next two columns are for the other component, and the first component is repeated in the last column. Since only one-directional arrows are used in the three interaction models, the fifth column is repeated to show the influence of the first component on the other components.

The two layers of the intrinsic and the influenced characteristics under each component are intended to show the interdependency of the building, people, and fire components, which further confirms that the building fire safety performance is a function of not only each component's characteristics but also their interactions. In addition, especially for the building characteristics, the layering of characteristics and the interactions within the building characteristics reveal critical information: 


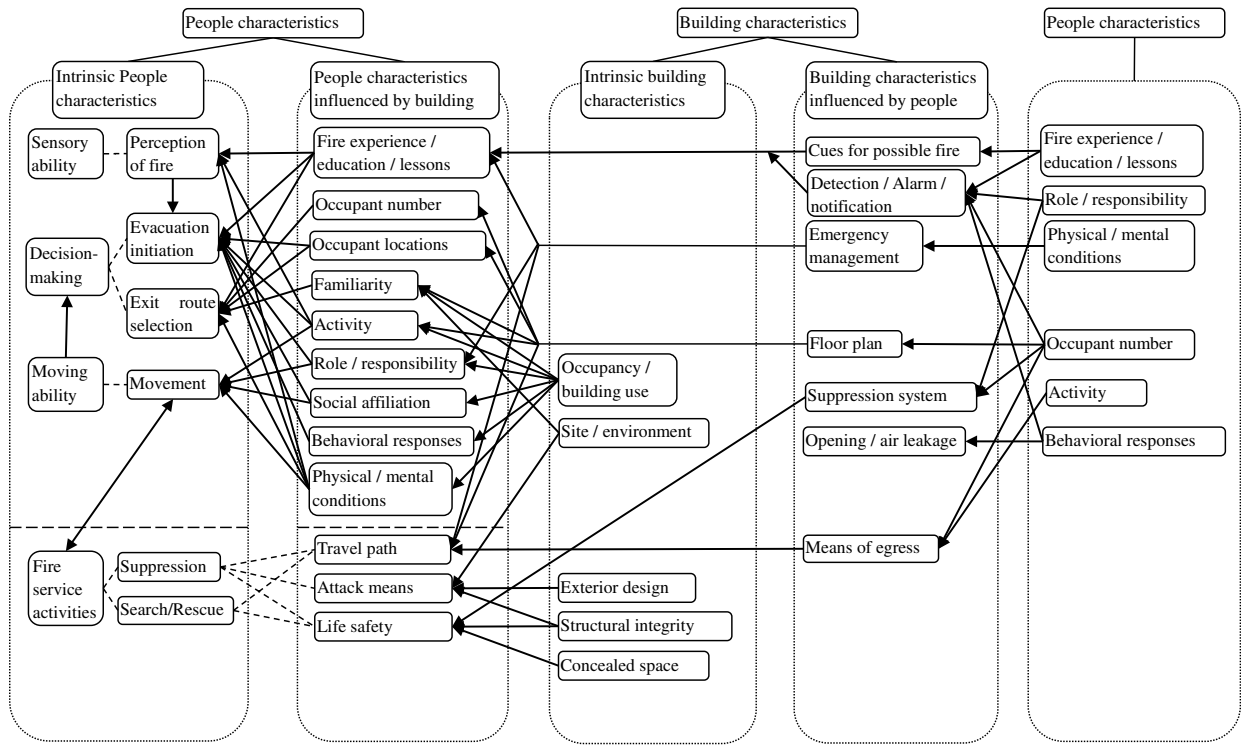

Figure 2. The relationship between building and people characteristics.

A. Soft characteristics such as site/environment, room size, floor plan, exterior design, emergency management and occupant characteristics influence and are influenced by hard characteristics.

B. Most soft characteristics in building components are determined by architects with little influence of fire protection engineers.

C. Hard characteristics such as electrical power equipment, HVAC system, means of egress are concerned by both fire protection engineers and other stakeholders such as building manager, electrical/mechanical/thermal engineers, and architects. The collaboration among the relevant stakeholders based on a clear understanding of the effects of the characteristics on the respective performances is required to avoid unnecessary competition between different objectives.

\section{Development of Quantitative Model Based on the ICIM}

Since building fire safety performance is involved with various characteristics of building, people, and fire components and the cause-effect relationships among them, a holistic perspective accounting for the effects of not only individual characteristics but also the various interactions among both hard and soft characteristics is required in order to properly assess the building fire safety performance. With the holistic understanding as a prerequisite, a quantification method 
commonly used in analytical hierarchy process (AHP) is adopted to further illustrate the application of the ICIM.

\subsection{Formulation of Characteristics for Quantification}

Despite the complexity of the ICIM, its conceptual origin is the simple GFRM in which largely two fire safety objectives are incorporated: property protection and life safety, which are represented by fire propagation and egress characteristics. As such, the ICIM can be modified or restructured locating the property protection and life safety at the top level with multiple branches of sub-level characteristics in a hierarchical manner. Top characteristics are influenced by intermediate characteristics which in turn are influenced by bottom characteristics. By modifying bottom characteristics, changes propagate through the system upwardly.

The hierarchical structures of quantitative models based on the ICIM are presented as two diagrams: one for property protection and the other for life safety, in Figures 3 and 4, respectively. In these diagrams, characteristics are modified from the ICIM; some are excluded such as electrical equipment, some are divided into more detailed characteristics such as occupant activity and building use, and some are combined into a single characteristic such as oxygen availability, to fit better for the quantification scheme. It should be noted that the ICIM and the quantitative model diagrams serve different objectives: the former for the holistic understanding of the building performance during fires and the latter for the quantitative performance evaluation. Red boxes, blue boxes, and white boxes

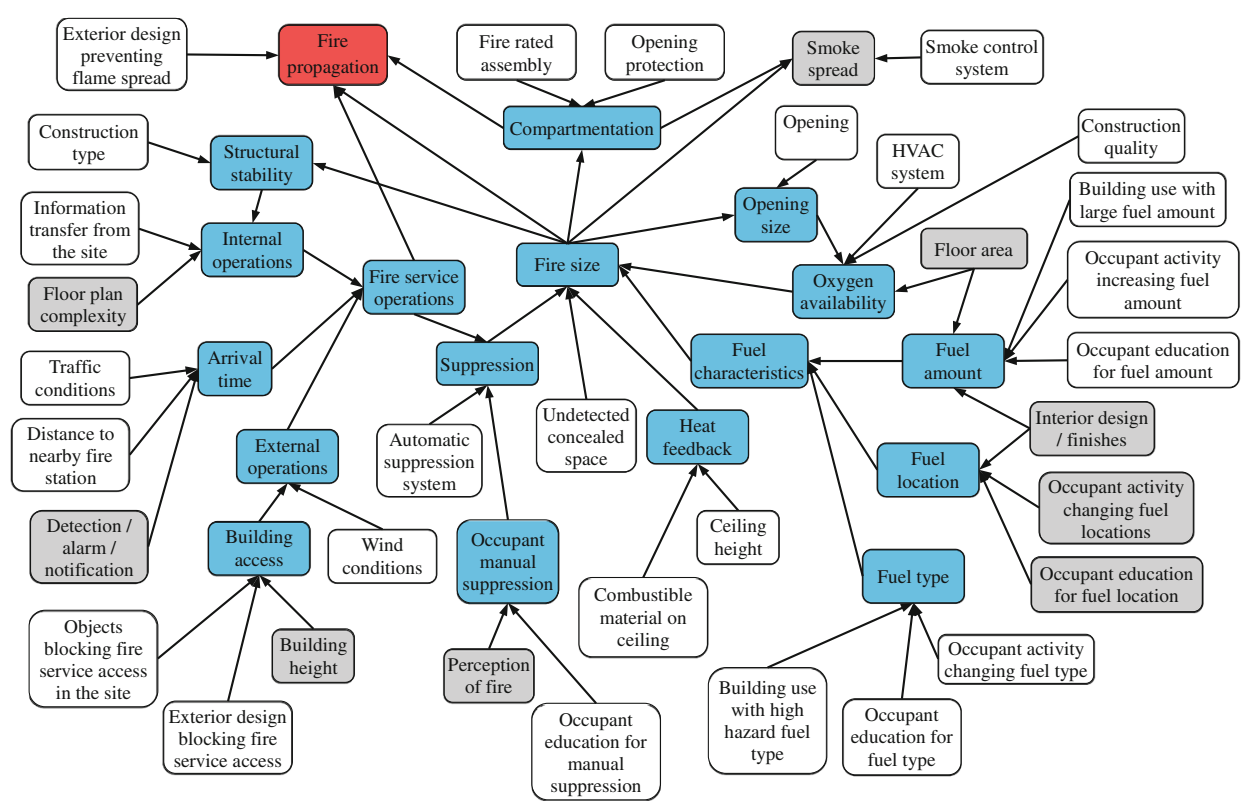

Figure 3. Hierarchy of attributes for property protection performance. 
represent the top, intermediate, and bottom level characteristics and characteristics in gray boxes are shared by both property protection and life safety performance.

In the quantitative models shown in Figures 3 and 4, two different types of influence relationships are defined: static and dynamic. Static relationships indicate that upper level characteristics are influenced by lower level characteristics while dynamic relationships represent mutual influences. Most of the interactions shown in Figures 3 and 4 are static relationships, but the relationship among the fire size, structural stability, internal operation, fire service operations, and suppression and the relationship among the fire size, opening size and oxygen availability are dynamic. This is because fire service suppression operations are influenced by structural stability as fire fighters are pulled out of the building in case that structural stability is decreased by large fire sizes. Once fire service stops suppression activity within the building, fire size tends to become larger. In the same way, a large fire size can break windows, which in turn provides more oxygen from which fire can be larger. A different quantification method is used for the relationship of dynamic influence, which will be explained in the section of application of the quantitative ICIM.

\subsection{Quantification Method}

To reflect the relative importance of characteristics within the hierarchy illustrated in Figures 3 and 4, the AHP is used. AHP is a decision-making procedure for multi-attribute problems developed by Saaty [23]. By assessing relative importance of lower level attributes in the hierarchy, upper level attributes are quantified by weighted sum method. The relative importance is calculated based on the

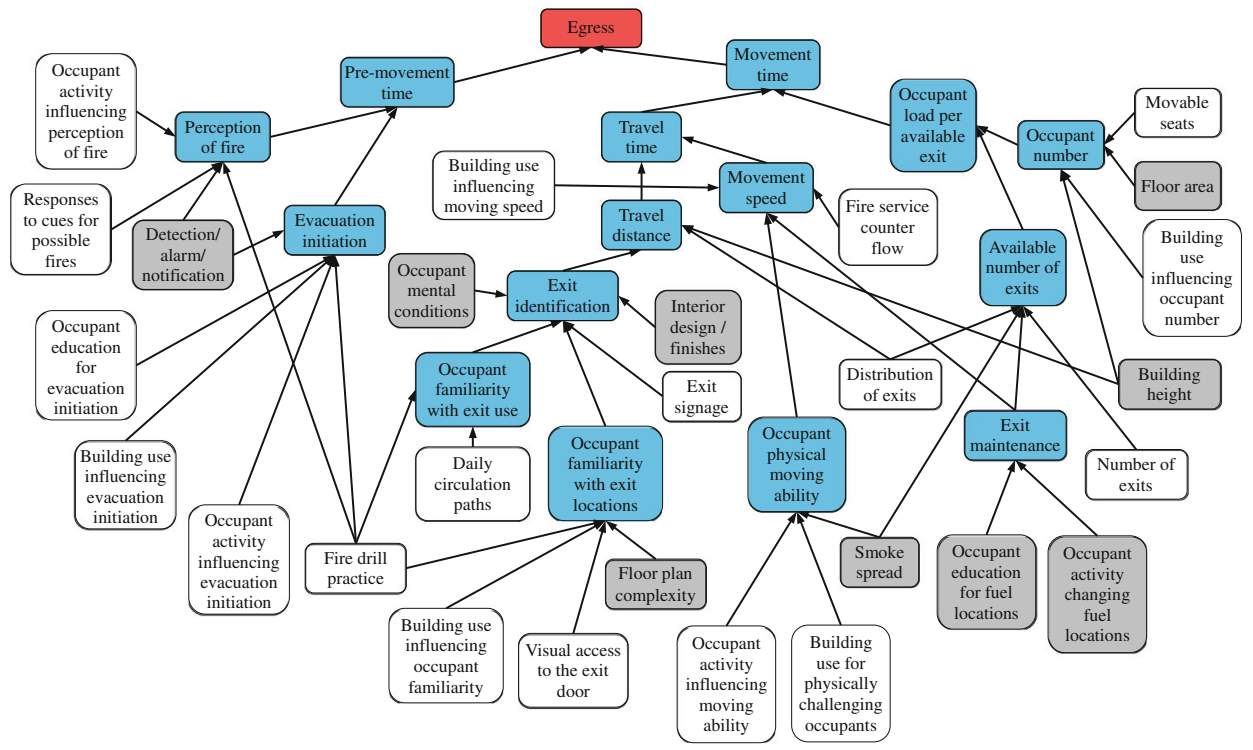

Figure 4. Hierarchy of attributes for life safety performance. 
eigenvalue/eigenvector of reciprocal matrix. This approach is appropriate for the quantitative model of the ICIM as applied to a specific building as the weights of influencing factors will be a function of specific designs, building uses, occupants, site conditions, etc. In the first instance, judgments of the FPE can be used to assign weights and values can also be determined jointly between stakeholders. Judgments are influenced by data and analysis. This approach has been used in other fire safety performance evaluation approaches [24, 25].

To illustrate the mathematical formulation and calculation procedure, an example, for the building access characteristic, is provided below.

According to the diagram in Figure 3, building access for the external fire service operations is influenced by three attributes (or characteristics): building height, objects blocking fire service access in the site, and exterior design blocking fire service access. Let us assume that each attribute has an absolute importance value to building access as listed in Table 1. Per this assumption, "building height" is $w 1 / w 2$ times more important than "objects blocking fire service access in the site", and $w 1 / w 3$ time more important than "exterior design blocking fire service access."

The reciprocal matrix which shows the relative importance of the attributes is written as:

$$
\mathbf{A}=\left[\begin{array}{lll}
\frac{w 1}{w 1} & \frac{w 1}{w 2} & \frac{w 1}{w 3} \\
\frac{w 2}{w 1} & \frac{w 2}{w 2} & \frac{w 2}{w 3} \\
\frac{w 3}{w 1} & \frac{w 3}{w 2} & \frac{w 3}{w 3}
\end{array}\right]
$$

Multiplying the reciprocal matrix A, with the importance vector $\mathbf{w}$,

$$
\mathbf{A w}=\left[\begin{array}{ccc}
\frac{w 1}{w 1} & \frac{w 1}{w 2} & \frac{w 1}{w 3} \\
\frac{w 2}{w 1} & \frac{w 2}{w 2} & \frac{w 2}{w 3} \\
\frac{w 3}{w 1} & \frac{w 3}{w 2} & \frac{w 3}{w 3}
\end{array}\right]\left[\begin{array}{l}
w 1 \\
w 2 \\
w 3
\end{array}\right]=\left[\begin{array}{l}
w 1+w 1+w 1 \\
w 2+w 2+w 2 \\
w 3+w 3+w 3
\end{array}\right]=3\left[\begin{array}{l}
w 1 \\
w 2 \\
w 3
\end{array}\right]=n \mathbf{w}
$$

where $n=$ the number of attributes

The form, $\mathbf{A w}=n \mathbf{w}$, has similarity with the eigenvalue/eigenvector format in linear algebra, which is $\mathbf{A w}=\lambda \mathbf{w}$, where $\lambda$ is the eigenvalue and $\mathbf{w}$ is the eigenvector. Note that the eigenvalue is equal to the number of attributes. From this relationship, it is found that once the reciprocal matrix, $\mathbf{A}$ is determined, eigenvector, $\mathbf{w}$ which indicates the relative importance of each attribute can be calculated.

\section{Table 1}

Assumed Influencing Variables for Building Access 
Matrix A is formulated by pair-wise comparisons of the attributes which typically uses values from 1 to 9 and their reciprocals as proposed by Saaty [26].

The number of pair-wise comparisons of the attributes is determined by the total number of the attributes. Generally, when more attributes are involved, the consistency of the pair-wise comparison becomes decreased, and the actual reciprocal matrix becomes prone to having some deviations in their components from the exact reciprocal matrix components. Such that, $\lambda$ is not always the same value with $n$, but the eigenvalue which is close to $n$, needs to be selected and its corresponding eigenvectors become the relative importance of the attributes. This relationship can be written as:

$$
\mathbf{A}^{\prime} \mathbf{w}^{\prime}=\lambda_{\max } \mathbf{w}^{\prime}
$$

where $\mathbf{A}^{\prime}$ is the actual reciprocal matrix (commonly non-consistent) obtained from subjective pairwise comparison, $\mathbf{w}^{\prime}$ is the estimated eigenvector corresponding to $\lambda_{\max }, \lambda_{\max }$ is the maximum eigenvalue which is close to the number of variable, $n$.

For the building access attribute for external fire service operations, the reciprocal matrix is formulated in Table 2 followed by the rationales for the relative importance. Note that the justification represents the authors' views, and that rationale and weighting could change by project and user, and that over time, consensus values and rationale could be developed and codified.

\section{a. Building height versus objects blocking fire service access in the site}

Both a large building height and objects blocking fire service access such as tall trees, water ponds, and limited access road in the site significantly hinder fire service's access to the building. However, it is possible to compromise the hindrance caused by blocking objects in the site to some extent using various fire service equipment or attempting different directions of access route to the building while it is practically impossible to conduct external suppression mission if building is too tall for fire service to reach. Therefore, it is concluded that building height is two times more important than the objects blocking fire service access in the site.

\section{Table 2}

\section{Reciprocal Matrix for Building Access}

\begin{tabular}{lccc}
\hline & $\begin{array}{c}\text { Building } \\
\text { height }\end{array}$ & $\begin{array}{c}\text { Objects blocking } \\
\text { fire service } \\
\text { access in the site }\end{array}$ & $\begin{array}{c}\text { Exterior design } \\
\text { blocking fire } \\
\text { service access }\end{array}$ \\
\hline Building height & 1 & 2 & 5 \\
Objects blocking fire service access in the site & $1 / 2$ & 1 & 2 \\
Exterior design blocking fire service access & $1 / 5$ & $1 / 2$ & 1 \\
\hline
\end{tabular}


b. Exterior design blocking fire service access versus building height

Compared to the exterior design blocking fire service access such as roofs with vegetation or solar panels, no or a small number of opening on the façade facing to the direction of fire service access, or multi-layer façade by which water stream may not effectively reach the internal space of a building., building height is a more critical factor for fire service. If the equipment of fire service is not sufficient to reach upper floors of a tall building, suppression mission outside the building for those floors is impossible while exterior design blocking fire service access is obstructive, but do not make it impossible. For this reason, it is concluded that building height is five times more important than the exterior design blocking fire service access.

c. Objects blocking fire service access in the site versus exterior design blocking fire service access

Compared to the exterior design features blocking fire service access, objects in the site tend to be generally large-scale and more difficult to cope through to access the building. Therefore, from the perspective of the effectiveness of fire service operation, it is concluded that objects blocking fire service access to the building in the site is two times more important than exterior design blocking fire service access.

The reciprocal matrix for the building access attribute has three eigenvalues, which are $3.0385,-0.0193+0.3415 \mathrm{i}$, and $-0.0193-0.3415 \mathrm{i}$. Among this, the first eigenvalue is the maximum and close to the number of matrix components which is 3 , which are the criteria to identify the right eigenvalue for the analysis. Corresponding eigenvectors to this eigenvalue are $-0.8902,-0.4132$, and -0.1918 . Normalizing these values being divided by their sum, the importance factors $\left(\mathbf{w}^{\prime}\right)$ are calculated as shown in Table 3 .

It is recognized that this example uses importance factors as generalized by the author for example. However, consensus on scales and importance factors can be developed for specific projects with key stakeholders, as well as over time by committees or others working on consensus, much in the way the weighting in the FSES was developed. This not only would help engineers in the application of this assessment approach, but would address a concern identified by several building regulatory entities wherein the lack of consistency in performance assessments and design solutions have pushed the regulators to 'prescribe' various performance design factors [21]. A tool such as outlined above could be beneficial in facilitating

\section{Table 3}

\section{Importance Factor for the Atributes of Fire Service Operation}

\begin{tabular}{lccc}
\hline & $\begin{array}{c}\text { Objects blocking } \\
\text { fuilding } \\
\text { height }\end{array}$ & $\begin{array}{c}\text { Exterior design } \\
\text { access in the site } \\
\text { blocking fire } \\
\text { service access }\end{array}$ \\
\hline Importance factors & 0.5954 & 0.2764 & 0.1283 \\
\hline
\end{tabular}


broad agreement within a jurisdiction on key performance parameters and their importance for being addressed within fire safety design development.

Along with the importance factor, each attribute has its own performance value. As the importance factors are normalized between 0 and 1 , attribute performance values are also scaled between 0 and 1 such that upper and lower level attributes are in the same scale consistently. In the current study, three different values of performance scale are used: high, medium, and low with high being good for fire safety and low being unfavorable. Numerical values of $1,0.5$, and 0.01 are assigned to them, respectively. It should be noted that these values do not represent absolute performance. In other words, 'high' does not mean 100 times as effective as 'low'. Rather, it indicates relative contributions with respect to the performance of upper attributes. Poor performance (0.01) is almost neglected due to its small value regardless of the importance factor, while good performance (1) is fully reflected in the calculation of upper attributes in the scale of 0 to 1 . Medium performance (0.5) may be used for the attributes whose performance is not clearly identified as low or as high. Using weighted sum method, the quantified value for an upper level attribute becomes as:

Quantified performance value of an upper level attribute $=\sum_{i=1}^{n}$ wixi $=$ $w 1 x 1+w 2 \times 2+w 3 x 3+w 4 x 4$ where $x_{i}=$ ith attribute performance value in a given building $(1,0.5$, or 0.01$)$.

Assuming a tall high-rise building with the existence of objects blocking fire service access in the site (or around the building), the attribute performance value for the building access is calculated in Table 4 .

\subsection{Application of the Quantitative Model}

To provide a more concrete illustration of the application of this process, a simplified version of quantitative model which can represent the full model is established in Figure 5 and applied to an actual building where a fire incident occurred. The result of evaluation analysis is compared to the fire incident outcome and used to explore alternative fire safety design solutions.

The simplified model is formulated by mostly extracting intermediate level attributes from the full model shown in Figures 3 and 4. Note that intermediate level attributes in Figures 3 and 4 become the bottom level attributes in the simplified model in Figure 5 which can be expanded further consisting of lower level attributes.

\section{Table 4}

Attribute Performance Calculation for Building Access for External Fire Service Operations

\begin{tabular}{lcccc}
\hline Lower level attributes & $\begin{array}{c}\text { Importance } \\
\text { factor }\end{array}$ & $\begin{array}{c}\text { Performance } \\
\text { value }\end{array}$ & $\begin{array}{c}\text { Weighted } \\
\text { value }\end{array}$ & $\begin{array}{c}\text { Upper level } \\
\text { attributes }\end{array}$ \\
\hline Building height & 0.5954 & 0.01 & 0.0595 & Building \\
Objects blocking fire service access in the site & 0.2764 & 0.01 & 0.0028 & access $=0.1371$ \\
Exterior design blocking fire service access & 0.1283 & 1 & 0.1283 & \\
\hline
\end{tabular}




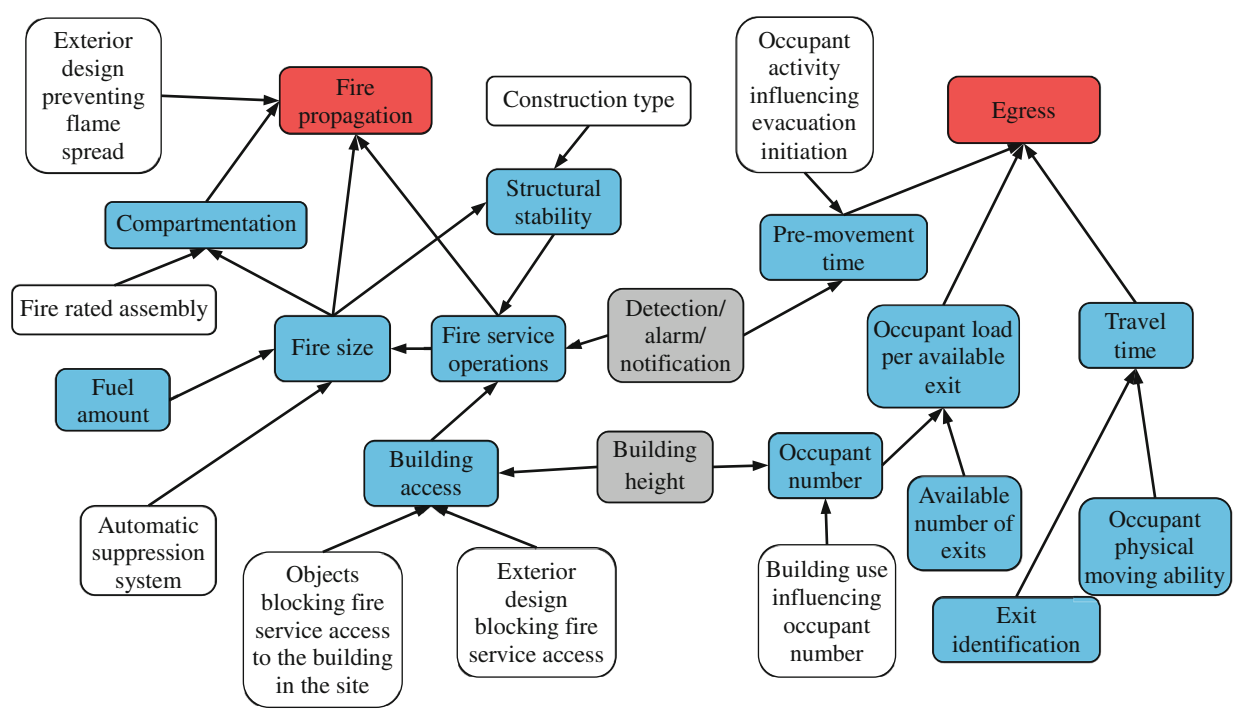

\section{Figure 5. Hierarchy of the simplified model.}

The fire incident which occurred in 2008 at the Faculty of Architecture Building (Bouwkunde) of Delft University of Technology in Delft, the Netherlands [27, 28] is selected as a target building of analysis. A brief description of the building features including building design and fire protection measures and occupant characteristics are as follows:

The Bouwkunde was a reinforced concrete, 13 story building consisting of a 3 story base and a 13 story tower structure. The tower was approximately $108 \mathrm{~m}$ long and $22 \mathrm{~m}$ wide. The floor plan of the tower section is divided into three areas: two large open design studios and office area at both ends and service area in the middle separated by 30 min rated fire barrier. An exit stairwell was provided in each compartmented area. The architectural design studio had two different ceiling heights: a single story high ceiling where a mezzanine floor being hung from the floor above and two story high ceiling for the rest area of the design studio. Combustible acoustic panel was installed on the bottom of the mezzanine floor (or on the ceiling of single story high area). An automatic suppression system was not installed, but manual fire extinguishers were equipped in the building. External escape stairs connected from the fourth floor to the ground were installed. Automatic door closer and smoke alarm system were installed throughout the building. Most perimeter of the building was surrounded by water and large trees were located near the building. The building was side of the building was surrounded by water. Occupants were mainly students and faculty members who knew the building layout well. The typical number of occupants is unknown, but could be significant considering the large floor area. Students were 


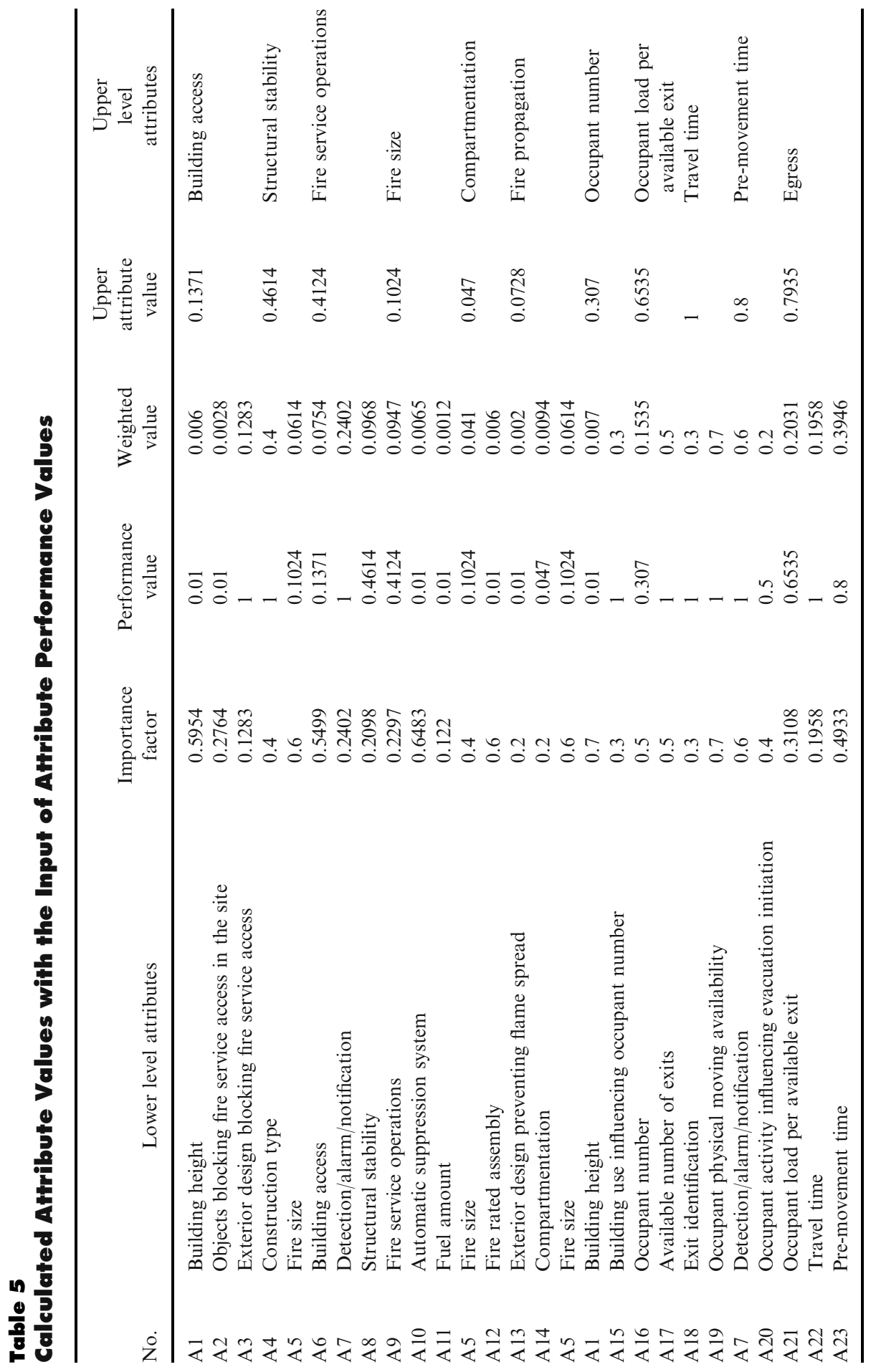




\begin{tabular}{|c|c|c|c|c|c|c|c|}
\hline & A6 & A7 & A8 & & A9 & $\mathrm{A} 10$ & A11 \\
\hline A6 & 1 & 2 & 3 & A9 & 1 & $1 / 3$ & 2 \\
\hline A7 & $1 / 2$ & 1 & 2 & A 10 & 3 & 1 & 5 \\
\hline \multirow[t]{2}{*}{ A8 } & $1 / 3$ & 1 & 1 & A11 & $1 / 2$ & $1 / 5$ & 1 \\
\hline & A13 & A14 & A5 & & A21 & A22 & A23 \\
\hline A13 & 1 & 1 & $1 / 3$ & A21 & 1 & 2 & $1 / 2$ \\
\hline A14 & 1 & 1 & $1 / 3$ & A22 & $1 / 2$ & 1 & $1 / 2$ \\
\hline A5 & 3 & 3 & 1 & A23 & 2 & 2 & 1 \\
\hline
\end{tabular}

expected to bring more and possibly highly combustible fuel contents such as foam board and balsa wood to study architectural design.

Based on this description, attribute performance values are assigned. The weighted values are calculated as shown in Table 5 with the assigned performance values and the importance factors developed following the same method for the building access characteristics. In addition to the building access attributes in Table 2, the reciprocal matrices to calculate importance factors for fire service operations, fire size, fire propagation and egress attributes are included in Table 6. The performance value of fire size attribute which is dynamically linked with fire service operations is determined iteratively to satisfy that the values of fire size as lower level attribute and upper level attribute are identical.

It should be noted again that the weighing factors in Tables 5 and 6 are based on expert judgment and it is expected that more robust means to develop estimates from a broad selection of experts in the future would be beneficial.

From the building fire safety evaluation, fire propagation attribute which represents property protection has a very low value while egress attribute which represents life safety has a relatively high value, which is actually in a good agreement with the major fire incident outcomes which is summarized as below.

Fire occurred in the sixth floor of the north section of the tower structure and rapidly spread to upper floors through the exterior windows. The separation distance between exterior windows were not sufficient to prevent vertical flame spread. Fire also spread horizontally compromising the 30 min fire barrier. A large fuel amount existed in the design studio area having a wide open space. Fire service arrived at the building, but did not effectively conduct suppression mission due to the objects blocking fire service access to the building and rapid fire spread within the building. A portion of building collapsed approximately $7 \mathrm{~h}$ after the ignition. Fortunately, all occupants evacuated the building safely.

Despite the collapse, the fire safety performance of the Faculty of Architecture Building may be satisfactory if life safety was the only performance objective. However, for property protection which is also a common objective in performance-based fire safety designs, the current safety features need to be modified 


\section{Table 7}

Fire Propagation Performance Values for Various Fire Safety Design Solutions

\begin{tabular}{llllllll}
\hline $\begin{array}{l}\text { Design } \\
\text { solution }\end{array}$ & A2 & A10 & A11 & A12 & A13 & $\begin{array}{c}\text { Fire propagation } \\
\text { performance value }\end{array}$ & \multicolumn{1}{c}{ Summary } \\
\hline Current & 0.01 & 0.01 & 0.01 & 0.01 & 0.01 & 0.0728 & \\
Design 1 & 1 & 0.01 & 0.01 & 0.01 & 0.01 & 0.097 & $\mathrm{~A} 2$ only \\
Design 2 & 0.01 & 1 & 0.01 & 0.01 & 0.01 & 0.5223 & $\mathrm{~A} 10$ only \\
Design 3 & 0.01 & 0.01 & 1 & 0.01 & 0.01 & 0.1574 & $\mathrm{~A} 11$ only \\
Design 4 & 0.01 & 0.01 & 0.01 & 1 & 0.01 & 0.1916 & $\mathrm{~A} 12$ only \\
Design 5 & 0.01 & 0.01 & 0.01 & 0.01 & 1 & 0.2708 & $\mathrm{~A} 13$ only \\
Design 6 & 1 & 0.01 & 1 & 1 & 0.01 & 0.3766 & $\mathrm{~A} 2+\mathrm{A} 11+\mathrm{A} 12$ \\
Design 7 & 1 & 0.01 & 0.01 & 1 & 1 & 0.4138 & $\mathrm{~A} 2+\mathrm{A} 12+\mathrm{A} 13$ \\
Design 8 & 1 & 0.01 & 1 & 1 & 1 & 0.4984 & $\mathrm{~A} 2+\mathrm{A} 11+\mathrm{A} 12+\mathrm{A} 13$ \\
\hline
\end{tabular}

Fire propagation attribute performance value

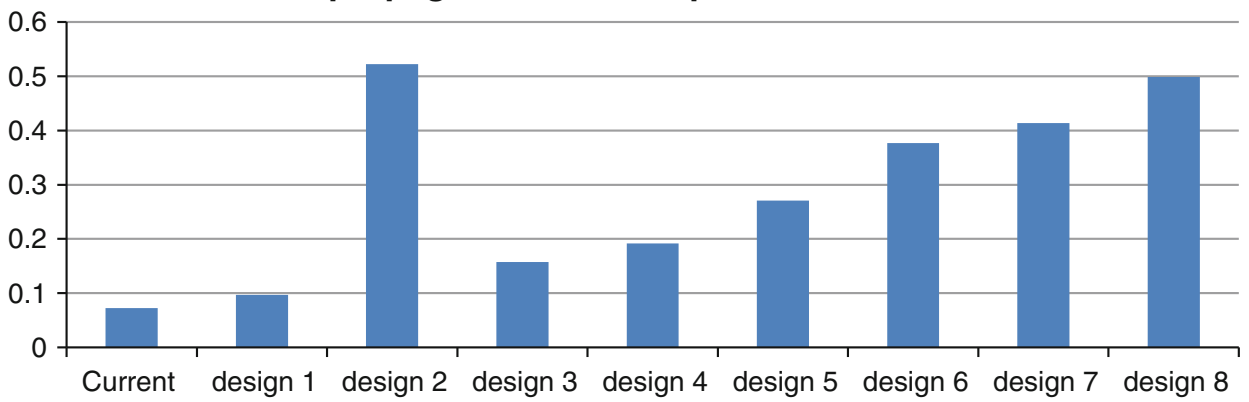

Figure 6. Comparisons of fire propagation attribute values for different fire safety designs.

based on the agreement of relevant stakeholders. It should be noted that the relevant stakeholders include engineers, designers, and consultants who are related to both hard and soft characteristics, and do not indicate only fire engineers. With the purpose of improving property protection performance, the attribute performance value of fire propagation is compared for multiple candidate fire safety designs. By changing the attribute performance values of A2, A10, A11, A12, and A13 from 0.01 to 1 as shown in Table 7, fire propagation performance values are re-evaluated. Medium performance $(0.5)$ is not considered in this example as the purpose is to show the performance variations per scenario, assuming only good or poor performance. It is found that automatic sprinkler system (A10) as a single attribute has the largest effect on improving the property protection performance. However, Design 8 in Table 7, a combination of allowing fire service access to the building (A2), controlling fuel amount (A11), and improved fire rated assembly (A12) and exterior design preventing flame spread (A13), can be also an effective fire safety solution for the Faculty of Architecture Building as shown in Figure 6. 
In a real fire safety evaluation project for a particular building, some of these attributes may be bounded by given conditions such as building site, project budget, or even stakeholders' preferences such that available attributes for design modification may be significantly reduced. In addition, it may be necessary to conduct more detailed analysis to determine the performance values for some attributes. For example, for the attribute of exterior design preventing flame spread, a sufficiently robust analysis method is recommended to calculate the extended flame height through openings and radiation effects on the materials on the floor above. The performance value of travel time attribute may be determined based on the computer simulation results of evacuation modeling programs. In this case, however, the user need to recognize whether the imbedded features of evacuation simulation programs for exit identification such as occupant familiarity, influence of interior design, exit signage, and visual access to the exit door and their effects on the simulation results are reasonable [16].

\section{Conclusion}

Building fire safety performance is a complex matter with various characteristics being involved from building, people, and fire components as a system. Utilizing the conceptual background in the systems approach in the 1970s, two qualitative models were developed: GFRM and ICIM. The GFRM reflects dynamic features of fire development, building responses, and people activities from a broad perspective to capture the generic phenomena of building fire safety. Chronological order and multiple fire safety strategies can be identified easily from this model compared to the FSCT. The ICIM is a more detailed version of the GFRM including various hard and soft characteristics and their interactions which were identified from the 15 actual previous fire incidents. By extracting characteristics from actual fire incidents, the validity of characteristics became increased when compared to the identification method through survey among fire engineers. In addition to this, compared to the previous systems approach, the ICIM can be distinguished by incorporating more and clearer soft characteristics, specifically building design and occupant characteristics.

Based on the holistic understanding of the interactions of characteristics, a quantification method commonly used in AHP was utilized to evaluate fire safety performance. A simplified version of the quantitative ICIM was applied to the actual fire incident which occurred at the Faculty of Architecture Building of the Delft University of Technology, the Netherlands, to show the framework of the quantification method and the step by step application procedure. By collecting relevant stakeholders' pair-wise comparison of the attributes, the chronic criticism on the subjectivity of the quantified values can be reduced in the proposed method, although further research is still required to reduce the criticism by obtaining more objectivity via adjusting the importance factors and attribute performance values to match historical fire incident outcomes. Regardless of this subjectivity, relative comparisons among multiple fire safety designs can be a useful tool to identify alternative design solutions. The proposed AHP-based tool can 
also help identify when and where more in-depth analysis may be needed by highlighting issues which arise from the confluences of characteristics for any particular building.

\section{References}

1. SFPE (2005) SFPE engineering guide to performance-based fire protection analysis and design of buildings

2. ABCB (ed) (2005) International fire engineering guidelines. Australian Building Codes Board, Canberra

3. Meacham BJ (2000) International experience in the development and use of performance-based fire safety design methods: evolution, current situation and thoughts for the future. Fire Safety Sci 6:59-76

4. Meacham BJ (1998) The evolution of performance-based codes and fire safety design methods. National Institute of Standards and Technology (NIST), NIST GCR 98-761

5. Phillips WGB, Beller DK, Fahy RF (2008) The SFPE handbook of fire protection engineering, 4th edn. National Fire Protection Association, Quincy, pp. 5-156

6. Nelson HE (1977) Directions to improve application of systems approach to fire protection requirements for buildings. Wood Fiber Sci 9(2):107-126

7. Watts J (1979) A theoretical rationalization of a goal-oriented systems approach to building fire safety. NASA STI/Recon Technical Report N 79:22329

8. Budnick E (2011) Review: SFPE classic paper review: Interim guide for goal oriented systems approach to building fire safety by Harold E. 'Bud'Nelson. J Fire Prot Eng 21(3):173-183

9. Fitzgerald RW (1985) An engineering method for building firesafety analysis. Fire Saf J 9(2):233-243

10. Fitzgerald R (1993) Building fire safety evaluation method. Worcester Polytechnic Institute, Worcester

11. Shields T, Silcock G, Bell Y (1986) Fire safety evaluation of dwellings. Fire Saf J 10(1):29-36

12. Stollard P (1984) The development of a points scheme to assess fire safety in hospitals. Fire Saf J 7(2):145-153

13. Lo SM (1999) A fire safety assessment system for existing buildings. Fire Technol 35(2):131-152

14. Chow W (2002) Proposed fire safety ranking system EB-FSRS for existing high-rise nonresidential buildings in Hong Kong. J Archit Eng 8(4):116-124

15. Lo SM, Hu BQ, Liu M, Yuen KK (2005) On the use of reliability interval method and grey relational model for fire safety ranking of existing buildings. Fire Technol 41(4):255-270

16. Park H, Meacham BJ, Dembsey NA, Goulthorpe M (2013) Enhancing building fire safety performance by reducing miscommunication and misconceptions. Fire Technol. doi:10.1007/s10694-013-0365-2

17. Johnson $P$ (1996) The process of fire safety design-development of fire engineering guidelines in Australia. Fire Technol 32(4):297-307

18. Leslie JA (2001) Behavioural solution to the learned irrelevance of emergency exit signage. Human behavior in fires: proceedings of the 2nd international symposium in fire. Interscience Communications, London, pp 23-33 
19. Wurzer G, Hinneberg H, Illera C, Swoboda S, Jonas A (2009) Architectural patterns enabling reconfigurable exit routes for complex buildings. In: Traffic and granular flow. Citeseer

20. Key JP (2002) Qualitative research. http://www.okstate.edu/ag/agedcm $4 \mathrm{~h} /$ academic/ aged5980a/5980/qualrsch/QUALRSCH/sld001.htm

21. NFPA (2012) Guide to the fire safety concepts tree. NFPA

22. Park H, Meacham BJ, and Dembsey NA (2012) Increasing building fire safety by bridging the gap between architects and fire safety engineers. Proceedings of the 9th international conference on performance-based codes and fire safety design methods. SFPE, Bethesda

23. Saaty TL (1980) The analytic hierarchy process: planning, priority setting, resource allocation. McGraw-Hill, New York

24. Shields J, Silcock G (1986) An application of the hierarchical approach to fire safety. Fire Saf J 11(3):235-242

25. Meacham BJ (2000) Application of a decision-support tool for comparing and ranking risk factors for incorporation into performance-based building regulations. In: Proceedings of the third international conference on performance-based codes and fire safety design methods

26. Saaty TL (1986) Axiomatic foundation of the analytic hierarchy process. Manage Sci 32(7):841-855

27. Meacham B, Engelhardt M, Kodur V (2009) Collection of data on fire and collapse, Faculty of Architecture Building, Delft University of Technology. In: National Science Foundation, CMMI Research and Innovation Conference, pp 22-25

28. Meacham B, Park H, Engelhardt M, Kirk A, Kodur V, van Straalen I, Maljaars J, van Weeren K, de Feijter R (2010) Both K fire and collapse, Faculty of Architecture Building. In: Delft University of Technology: data collection and preliminary analysis. Proceedings of the 8 th international conference on performance-based codes and fire safety design methods. Lund University, Sweden 